\title{
Thematic issue: Hydrothermal conversion of biomass
}

\author{
Toufiq Reza ${ }^{1}$
}

Published online: 10 September 2021

(c) The Author(s), under exclusive licence to Springer-Verlag GmbH Germany, part of Springer Nature 2021

Bioenergy holds a vital key to unleash sustainable energy that could secure global energy demand. Several generations of biofuels are already playing their parts but conversion of wet biomass (e.g., municipal solid waste, sewage sludge, digestate from anaerobic digestion, food waste) to biofuel and bioenergy is still developing. Hydrothermal conversion is one of the emerging processes that converts wet biomass into fuel, energy, and materials. One of the major benefits of hydrothermal conversion compared to other thermochemical processes is the utilization of residual moisture as reaction medium. There is no need to dry the biomass prior to the conversion process. Depending on the reaction temperature and desired product, hydrothermal conversion can be categorized as hydrothermal carbonization (HTC), hydrothermal liquefaction (HTL), and supercritical water gasification (SCWG). Desired product of HTC is solid hydrochar, when wet biomass is treated between 180 and $260{ }^{\circ} \mathrm{C}$. HTL yields liquid fuel from wet biomass at above HTC temperature but below critical temperature of water. On the other hand, hydrogen or methane-rich gaseous products are formed during SCWG at above critical temperature of water. Although fundamental understanding of hydrothermal conversion of model compounds is now understood, knowledge on hydrothermal conversion of real biomass is still scarce.

This thematic issue titled "Hydrothermal Conversion of Biomass" highlights recent advances in real biomass conversion to fuels, chemicals, and materials. This thematic issue comprises twenty papers including the editorial. Authors from eleven countries have contributed to this issue. It is evident that interest in hydrothermal conversion of wet biomass is emerging globally. In this thematic issue, the major areas covered by the articles are the following:

Toufiq Reza

treza@fit.edu

1 Department of Biomedical and Chemical Engineering and Sciences, Florida Institute of Technology, 150 West University Boulevard, Melbourne, FL 32901, USA
- HTC of municipal solid waste [1, 2], food waste [3-5], and industrial waste [6]

- Comparison of hydrochar with pyrochar performance on soil [7]

- Comparison of hydrothermal with acidic and alkaline treatment [8]

- Catalytic HTC [9-11], HTL [12-15], and SCWG [16]

- Process optimization $[3,17,18]$, process integration $[6$, 19], and techno-economic assessment [4]

Overall, hydrothermal conversion of biomass has shown promising results toward commercialization. The articles covered various real feedstocks, process conditions, process optimization, kinetics, product development, product application, and techno-economic assessment. We hope that readers will find the articles in this thematic issue both informative and inspiring for their future research. Finally, I, on behalf of the editors, would like to thank the authors for submitting their valuable work to this thematic issue. The reviewers are also acknowledged for their contributions with the article revisions, which has significantly improved this thematic issue.

\section{References}

1. A.K.M.K. Aurnob, A. Arnob, K.B. Kabir, M.S. Islam, M.M. Rahman, K. Kirtania, Hydrothermal carbonization of biogenic municipal waste for biofuel production, Biomass Conversion and Biorefinery (2021).

2. S.S. Dima, A. Arnob, U. Salma, K.B. Kabir, K. Kirtania, Fate of nutrients during hydrothermal carbonization of biogenic municipal waste, Biomass Conversion and Biorefinery (2020).

3. R. Divyabharathi, P. Subramanian, Biocrude production from orange (Citrus reticulata) peel by hydrothermal liquefaction and process optimization, Biomass Conversion and Biorefinery (2021).

4. S. Mazumder, P. Saha, K. McGaughy, A. Saba, M.T. Reza, Technoeconomic analysis of co-hydrothermal carbonization of coal waste and food waste, Biomass Conversion and Biorefinery Inpress (2020). 
5. S. Mazumder, P. Saha, M.T. Reza, Co-hydrothermal carbonization of coal waste and food waste: fuel characteristics, Biomass Conversion and Biorefinery in-press (2020).

6. T. Ariyawansha, D. Abeyrathna, T. Ahamed, R. Noguchi, Integrated bagasse utilization system based on hydrothermal liquefaction in sugarcane mills: theoretical approach compared with present practices, Biomass Conversion and Biorefinery (2020).

7. O. Jafari Tarf, M.O. Akça, Y.O. Donar, S. Bilge, O.C. Turgay, A. Sinağ, The short-term effects of pyro-and hydrochars derived from different organic wastes on some soil properties, Biomass Conversion and Biorefinery (2021).

8. A. Agarwal, K. Paritosh, P. Dangayach, P. Gehlot, N. Pareek, V. Vivekanand, Hydrothermal, acidic, and alkaline pretreatment of waste flower-mix for enhanced biogas production: a comparative assessment, Biomass Conversion and Biorefinery (2021).

9. M. Ameen, N.M. Zamri, S.T. May, M.T. Azizan, A. Aqsha, N. Sabzoi, F. Sher, Effect of acid catalysts on hydrothermal carbonization of Malaysian oil palm residues (leaves, fronds, and shells) for hydrochar production, Biomass Conversion and Biorefinery (2021).

10. S.S. Memon, N. Memon, S. Memon, A. Lachgar, An excellent sulfonated hydrothermal carbon catalyst from Mangifera indica L. (mango peels) for biodiesel production: preparation, characterization, optimization, and kinetic study, Biomass Conversion and Biorefinery (2021).

11. N. Sweygers, M. Kamali, T.M. Aminabhavi, R. Dewil, L. Appels, Efficient microwave-assisted production of furanics and hydrochar from bamboo (Phyllostachys nigra "Boryana") in a biphasic reaction system: effect of inorganic salts, Biomass Conversion and Biorefinery (2021).

12. L.J. Konwar, B. Oliani, A. Samikannu, P. Canu, J.-P. Mikkola, Efficient hydrothermal deoxygenation of tall oil fatty acids into n-paraffinic hydrocarbons and alcohols in the presence of aqueous formic acid, Biomass Conversion and Biorefinery (2020).
13. A. Kumar, B. Biswas, K. Saini, A. Kumar, J. Kumar, B.B. Krishna, T. Bhaskar, Copper and manganese bimetallic catalysts for oxidation of prot lignin: effects of metal oxide on product yield, Biomass Conversion and Biorefinery (2021).

14. J.S. Saral, P. Ranganathan, Catalytic hydrothermal liquefaction of Spirulina platensis for biocrude production using Red mud, Biomass Conversion and Biorefinery (2021).

15. K. Saini, A. Kumar, B. Biswas, T. Bhaskar, Low-temperature alkali lignin depolymerization to functional chemicals, Biomass Conversion and Biorefinery (2021).

16. N. Saha, A. Saba, K. McGaughy, M.T. Reza, Effect of supercritical water temperature and $\mathrm{Pd} / \mathrm{C}$ catalyst on upgrading fuel characteristics of gumweed-derived solvent-extracted biocrude, Biomass Conversion and Biorefinery (2020).

17. M. Heidari, O. Norouzi, K. MacDermid-Watts, B. Acharya, Y. Zhang, A. Dutta, Product evaluation of hydrothermal carbonization of biomass: semi-continuous vs. batch feeding, Biomass Conversion and Biorefinery (2020).

18. M.J. Laranja, R.C.J. da Silva, M.C. Bisinoti, A.B. Moreira, M. Boscolo, O.P. Ferreira, C. de Almeida Melo, Factorial design of experiments for extraction and screening analysis of organic compounds in hydrochar and its process water of sugar cane bagasse and vinasse, Biomass Conversion and Biorefinery (2020).

19. J.V. dos Santos, L.G. Fregolente, M.J. Laranja, A.B. Moreira, O.P. Ferreira, M.C. Bisinoti, Hydrothermal carbonization of sugarcane industry by-products and process water reuse: structural, morphological, and fuel properties of hydrochars, Biomass Conversion and Biorefinery (2021).

Publisher's note Springer Nature remains neutral with regard to jurisdictional claims in published maps and institutional affiliations. 